\title{
вMJ Global Health Is sex ratio at birth an appropriate measure of prenatal sex selection? Findings of a theoretical model and its application to India
}

\author{
Sylvie Dubuc, ${ }^{1}$ Devinderjit Singh Sivia ${ }^{2}$
}

\begin{abstract}
To cite: Dubuc S, Sivia DS. Is sex ratio at birth an appropriate measure of prenatal sex selection? Findings of a theoretical model and its application to India. BMJ Glob Health 2018;3:e000675. doi:10.1136/ bmjgh-2017-000675
\end{abstract}

Handling editor Seye Abimbola

- Additional material is published online only. To view please visit the journal online (http://dx.doi.org/10.1136/ bmjgh-2017-000675).

Received 8 December 2017 Revised 7 May 2018 Accepted 9 May 2018
D) Check for updates

${ }^{1}$ Department of Geography, University of Reading, Reading, UK

${ }^{2}$ Saint John's College, University of Oxford, Oxford, UK

Correspondence to

Dr Sylvie Dubuc;

s.dubuc@reading.ac.uk

\section{ABSTRACT}

Son preference and prenatal sex selection against females have resulted in significant sex ratio at birth (SRB) imbalances well documented in several Asian countries, including India and China. The SRB bias is generally used as indicator for the extent and trends of prenatal sex selection against females. Decreasing fertility levels are expected to increase sex selection and thus SRB bias, since desiring fewer children increases the risk for families to remain sonless (fertility squeeze effect). We developed and employ mathematical models linking family size, birth order and childbearing strategies with population SRB bias. We show that SRB bias can increase despite fewer sex selection interventions occurring, inconsistent with the expectation of the fertility squeeze effect. We show that a disproportionality effect of fertility reduction amplifies SRB bias, in addition to the fertility squeeze effect, making SRB bias an inaccurate indicator for changes in sex selection practices within a population. We propose to use sex selection propensity (proportion of couples intervening) to measure behavioural change and evaluate policies targeting sex selection practices. We apply our findings to India, showing for instance that sex selection propensity in Punjab and Delhi was lower than in Rajasthan or Uttar Pradesh, despite significantly higher SRB bias in the former. While we observe a continuous overall increase in the SRB over the 2005-2010 period in India, our results indicate that prenatal sex selection propensity started declining during that period.

\section{INTRODUCTION}

Prenatal sex selection against females (PSS) is generally evidenced by a masculinisation of the sex ratio at birth (SRB; the ratio of boys to girls). It has been reported in South Korea, ${ }^{1}$ China, ${ }^{2}$ India, ${ }^{3}{ }^{4}$ and more recently in Vietnam, ${ }^{5} \mathrm{Nepal}^{6}$ and the Caucasus. ${ }^{7}$ SRB bias has also been found in Western countries with substantial Asian diasporas, notably in the UK, ${ }^{8}$ the USA and Canada. ${ }^{9-11}$ Substantially contributing to the masculinisation of the juvenile sex ratios since the 1980s, PSS is thought to have led to more than 30 million 'missing' female births, mostly in Asia, with

\section{Key questions}

What is already known?

- Son preference and prenatal sex diagnostics have led to prenatal sex selection practices against females in Asian countries.

- The imbalance in sex ratio at birth (SRB) is generally used as indicator for the extent of prenatal sex selection.

- Decreasing fertility increases the likelihood of remaining sonless; therefore, more couples feel pressured to secure a male offspring through prenatal sex selection.

- The quantitative relationship between fertility and SRB remains unclear.

\section{What are the new findings?}

- Using mathematical models we quantitatively relate fertility and SRB with the propensity of prenatal sex selection, thereby identifying a 'disproportionality effect of fertility on SRB bias'.

- SRB bias is not a reliable indicator for the extent of prenatal sex selection practices and related policy making.

\section{What do the new findings imply?}

- We propose to use sex selection propensity as reliable indicator for prenatal sex selection practices, allowing to measure and meaningfully compare the extent of prenatal sex selection across regions and over time, and to evaluate policies.

an estimated 1.7 million in 2015 alone. ${ }^{12}$ Hitherto, PSS is thought to have largely resulted from fetal sex determination (mainly ultrasound), followed by the abortion of female fetuses. More recently, PSS has also become technically possible through advances in medically assisted reproduction techniques ${ }^{\mathrm{i}} .^{13} 14$

${ }^{i}$ PSS is now possible through advances in medically assisted reproduction techniques, in particular in vitro fertilisation combined with prefertilisation selection of male spermatozoa (sperm sorting) or preimplantation genetic diagnosis and selection of male embryos. 
Many policy interventions at the local, regional or national levels have been introduced ${ }^{\mathrm{ii}}$ to reduce sex selection against females. The continuous rise in the SRB imbalance has been interpreted as evidence of prenatal sex selection diffusion and a failure of such policy interventions. ${ }^{6}{ }^{15-19}$ However, other researchers argue that without legislation, the SRB bias would have likely increased. ${ }^{20}$ In India, the continued rise in sex imbalances seen in the 2001 census engendered more restrictive legislation on access to prenatal sex selection methods (Pre-Conception and Pre-Natal Diagnostic (PNDT) Act, 1994, revised in 2003) and introduced alternative policies, including pregnancy tracking and monitoring schemes, child protection schemes and the multiplication of conditional cash transfer (CCT) schemes. ${ }^{18} 21$ The efficiency of such policy interventions remains difficult to evaluate. For example, the interagency statement 'Preventing gender-biased sex-selection' (Office of the High Commissioner for Human Rights (OHCHR), United Nations Population Fund (UNFPA), Unicef, UN Women and WHO) called for the development and use of indicators for tracking change and the impact of interventions. ${ }^{22}$

In countries like India, where the fertility transition is well under way, the dual desire for small families and male offspring exerts strong pressure on sonless parents to select for a son. ${ }^{1423}$ This is because the probability of remaining sonless, when left to chance, increases exponentially with fewer children. ${ }^{8}$ Guilmoto ${ }^{24}$ introduced the concept of the 'fertility squeeze' whereby, with fewer desired children, the cost of having additional children until male offspring is achieved by chance becomes decreasingly acceptable (expressed as acceptable proportion of female births, APFB), resulting in more parents reverting to sex selection and at lower birth order. Similarly, evidence in South and East Asia has shown that the distortion in the SRB is particularly pronounced at higher birth orders, when only daughters were born previously. ${ }^{125-27}$ A recent study by Jayachandran, ${ }^{28}$ based on survey data modelling, estimated that fertility reduction could explain up to half of India's sex ratio increase over the 1981-2011 period. A number of studies have further evidenced the male-preferring stopping rule of childbearing, ${ }^{29}{ }^{30}$ where parents of daughters only are more likely to progress to the next parity in an attempt to achieve a male birth and stop childbearing after a son is born, resulting in a strong male-biased sex ratio at last birth. ${ }^{31} 32$

Gender imbalances at birth provide the only readily available (indirect) method to evidence PSS quantitatively. However, the SRB is problematic for evaluating potential changes in sex selection attitudes and practices because desired family size influences reproductive behaviours associated with son preference, ${ }^{431} 33$ so that the extent of sex selection practices in a population cannot be directly evidenced from SRB bias. ${ }^{24}$

\footnotetext{
${ }^{\text {ii }}$ See UNFPA 2014 and references therein.
}

We were interested in estimating how many couples would have to sex-select in order to account for SRB bias sex selection in populations with varying fertility levels. We modelled the relationship between fertility and sex selection propensity (the proportion of intervening couples) to explain SRB bias, taking into account the fertility squeeze, gendered parity progression and the male-preferring stopping rule. Importantly, we demonstrate that SRB bias is hypersensitive to changes in fertility, because the fertility squeeze acts synergistically with a disproportionality effect of fertility on SRB. We illustrate this for India, based on reported fertility and sex ratio imbalances. We show that national trends and regional patterns of sex selection propensity differ markedly from SRB trends and patterns. Our findings call into question the interpretation and use of SRB to inform and evaluate policy and reproductive medical practices. Alternatively, we propose a measure of sex selection propensity as a more direct and relevant indicator of the population at risk to sex-select, indicating how widespread the practice is and to monitor behavioural change over time.

\section{METHODS}

\section{The theoretical model}

We developed probabilistic models, making assumptions regarding the order of intervention depending on the gender composition of previous siblings to integrate the fertility squeeze and differential childbearing stopping rule that can impact SRB outcomes. Initially, we designed a model assuming universal son preference and unconstrained access to sex selection technologies in a given (theoretical) population. We assumed interventions would occur at a single birth order (online supplementary appendix) in order to facilitate analytical progress in understanding the demographic mechanisms linking micro and aggregated levels. We used a simple model to account for the fertility squeeze effect, formulated as follows: Let the average number of children per family be $\lambda$ (table 1) and the natural propensity for female births be $p$. Since the fertility squeeze effect cannot be directly observed, we introduce a latent variable, $n$, which is directly proportional to the aforementioned APFB

\begin{tabular}{|c|c|}
\hline Variables & Description \\
\hline $\mathrm{R}$ & Proportion of male births; sex ratio at birth. \\
\hline$\lambda$ & $\begin{array}{l}\text { Average number of children per family within a } \\
\text { population. }\end{array}$ \\
\hline$\Phi$ & $\begin{array}{l}\text { Proportion of intervening couples, that is, } \\
\text { couples reverting to sex selection. }\end{array}$ \\
\hline$\Psi$ & $\begin{array}{l}\text { Proportion of intervening parents (excluding } \\
\text { childless couples). }\end{array}$ \\
\hline$n$ & $\begin{array}{l}\text { Birth order threshold of intervention: universal } \\
\text { threshold in model A; minimum universal } \\
\text { threshold in model B. }\end{array}$ \\
\hline
\end{tabular}


$\left(\mathrm{APFB}=100-\left(1 / n^{*} 100\right)\right.$; Guilmoto 2009$) .{ }^{5}$ In the model, $n$ expresses an intervention threshold, that is, at what birth order a couple would sex-select to ensure a male offspring. Families with $n$ or more children, but no son, would seek medical intervention to ensure that at least one birth is male.

Next, we accounted for the facts that (1) parents are likely to intervene at different birth orders, likely depending on their desired number of children; and (2) parents using sex selection to ensure a son most frequently stop childbearing thereafter. ${ }^{272}$ Therefore, we introduce the stopping rule (online supplementary appendix), that is, all parents would seek intervention only at last birth if sonless ${ }^{\mathrm{iii}}$. This constraint generates a varying distribution of intervention thresholds, accommodating any combination of fertility and SRB levels. Instead of the universal threshold above, ' $n$ ' becomes the minimum birth order at which parents would intervene; for instance, for $n=2$, families with a total of two children and where the first child was a girl would have sex-selected for the second and last child. This allowed analysis of the interrelation between sex selection, average family size and SRB distortion in a population, independent of factors limiting son preference or its implementation.

We assume in vitro fertilisation-like intervention throughout, so that all sonless parents at $n-1$ births would intervene at the next birth. In case of female-selective abortion, only women carrying a female fetus would opt for intervention and about half (only those with a diagnosed female fetus) would have to resort to more than one intervention, ultimately resulting in a similar number of interventions as per using a preconception method (see online supplementary appendix). We used the Poisson distribution to model the distribution of the number of children, $N$, in families when given only the mean value, $\lambda$; the case of $\lambda=1.7$ is illustrated in online supplementary figure S1A. We assigned the probability of having $G$ girls given $N$ and $p$, using a binomial distribution as only two possible outcomes at each birth, a boy or a girl, are possible; the case of $n=4$ and $p=0.486$ is illustrated in online supplementary figure S1B. The value of $\mathrm{p}=0.486$ was chosen for consistency with the norm of around 946 girls for every 1000 boys at birth (or 105.7 boys per 100 girls),${ }^{3435}$ and follows from the requirement that $p /(1-p) \approx 0.946$.

Having specified the model, the expected SRB ( $R$ in equations and figures) can be calculated for different values of $\lambda$ and $n$ (with $p$ fixed at 0.486 ) by using equations (9), (10) and (18) derived in online supplementary appendix. The corresponding formula for the proportion of couples needing to undertake a gender-selective intervention (ie, the intervening fraction denominated as $\Phi$ )

\footnotetext{
iii This remains an idealised model; possibly not all parents would stop childbearing after intervention, for instance in the case of the death of a child/son or because some parents may want more than one son (although empirical evidence suggests that these circumstances are increasingly unlikely where fertility transition is advanced).
}

to ensure that the $n^{\text {th }}$ child is male if the first $n-1$ births were female(s) is given in equations (11) and (19). $\Phi$ denotes the maximal proportion of intervening couples as each couple is assumed to potentially intervene once to account for aggregate SRB bias. Consequently, $\Phi$ also allows ready calculation of the prevalence of sex-selective interventions (absolute number of interventions), irrespective of multiple interventions by couples.

\section{Application to India}

We applied our model to India using reported SRBs and fertility levels, providing novel measures of sex selection propensity over time and across states, using equation 19 (online supplementary appendix). We used United Nations data on SRB and total fertility aggregated at the national level over 1970-2010 and calculated the corresponding proportion of couples intervening and analysed trends in sex selection propensity. Finally, we used reported values of SRB $(R)$ and total fertility $(\lambda)$ by key Indian states provided by the national Sample Registration System (SRS) to calculate the proportion of couples intervening and mapped the geographical distribution of sex selection prevalence.

\section{RESULTS \\ Theoretical results}

The general nature of the dependence of $R$ and $\Phi$ on the average size of the family $(\lambda)$ for different sex selection thresholds is shown in figure 1. In accordance with the fertility squeeze hypothesis, the model shows that generally the SRB $(R)$ and the proportion of couples intervening $(\Phi)$ increase with decreasing birth order threshold of sex selection couples opt for. $R$ is little distorted when the average number of children is extremely low in figure $1 \mathrm{~A}$, and consistently figure $1 \mathrm{~B}$ shows how the proportion of couples reverting to sex selection, $\Phi$, goes to 0 for all threshold $n$ when $\lambda$ is very small. This is because most families are then childless and never reach the critical intervention threshold $(n)$. Consequently, the distributions of $\Phi$ and $R$ as a function of $\lambda$ both exhibit a maximum (see figure 1 for $\mathrm{n}=3$ and below). We observed a sharp increase in $R$ with fertility reduction until $R$ and $\Phi$ reach their maxima, illustrating that the SRB $(R)$ is highly sensitive to changes in fertility rates within a population. The decreasing $\Phi$ with higher $\lambda$ is expected because parents desiring many children are most likely to have a son without sex-selecting (figure 1B).

Surprisingly, figure 1 shows an initial rise in the distortion of the sex ratio as the average number of children declines, for any given $n$, even though the proportion of couples using gender-selective intervention diminishes. Indeed, the peak of sex ratio distortion occurs at a much lower average number of children per family than does the peak of interventions (figure 1), showing that with fewer children overall, a greater distortion in the SRB $(R)$ may occur despite a reduction of the proportion of couples intervening $(\Phi)$ in a given population. This 


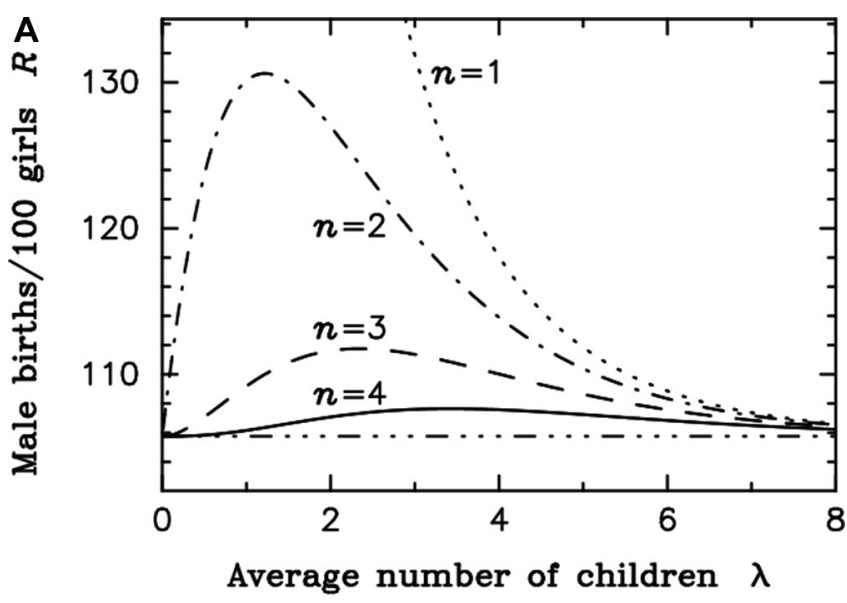

B

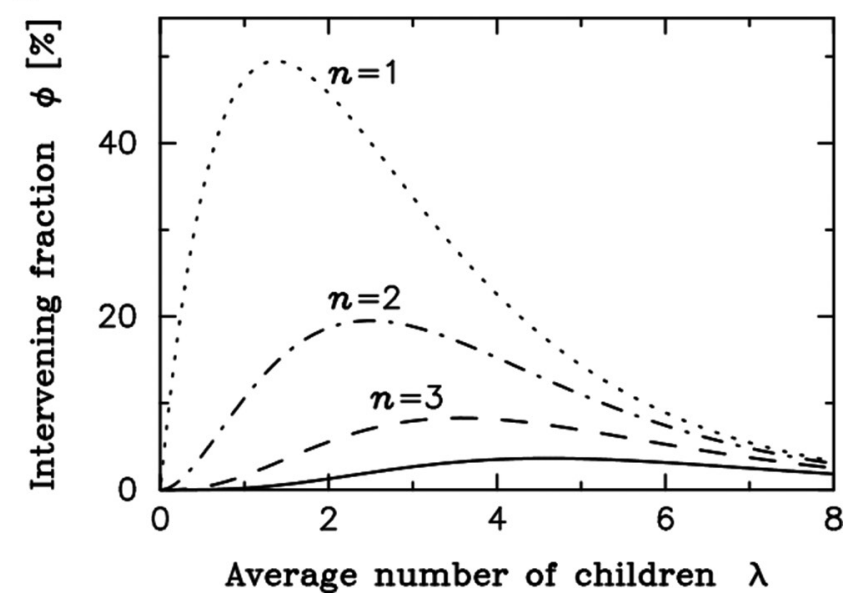

Figure 1 The stopping rule model. $(A, B) n$ is the minimum threshold (birth order) at which parents would use sex selection if necessary to ensure a son. Moving down from the top left-hand corner, the four curves show the cases for $n=1$ (dotted), $n=2$ (dot-dash), $n=3$ (dashed) and $\mathrm{n}=4$ (solid). For instance, at minimum intervention threshold $\mathrm{n}=2$, the distortion in the sex ratio at birth $(\mathrm{R})$ is increasing continuously with a reduction in the average number of children in the population $(\lambda)$ until it reaches its peak value of 130.6 boys per 100 girls at $\lambda$ equal to 1.196 . Below that point, there is increasingly less couples reaching the intervention threshold of two children, explaining that the sex ratio bias is decreasing. The fraction of intervening couples initially increases with fertility reduction to a maximum of $19.5 \%$ when reaching about 2.5 children in average before starting to decrease with further fertility reduction.

outcome is inconsistent with the fertility squeeze effect alone, which is expected to act proportionally on the fraction of couples intervening.

Our models include all couples, including those with no children. A decrease in the average number of children means more couples are childless, which could potentially significantly shift the $\Phi$ maxima position. Therefore, to exclude the possibility that the inclusion of childless couples accounts for the surprising result demonstrated in figure 1 , we calculated the proportion of intervening parents ( ), instead of couples, and found a proximal maxima for $\Phi$ and , excluding this possibility, as shown for the $n=2$ scenario in online supplementary figure S2. The increase in childlessness with fertility reduction contributes to lower $\Phi$ to some extent, but excluding childless couples still results in a discrepancy between the maxima of the SRB and the maxima of the proportion of parents intervening ( ) on the fertility scale. Therefore, a yet unaccounted factor must impact on SRB bias.

The disproportionality effect of fertility on the SRB

In order to disaggregate the impact of the fertility squeeze effect from other potential fertility influences on SRB, we computed the relationship between $\lambda, \Phi$ and $R$ directly, using equation 19 (online supplementary appendix). Figure 2 shows that at any given constant $\Phi>0$, the SRB $(R)$ increases exponentially with decreasing fertility $(\lambda)$, illustrated for $4 \%-20 \%$ of sex-selecting couples $(\Phi)$. We term this the disproportionality effect of fertility on the SRB, which is explained by the fact that within a small birth cohort, the number of 'extra boys' (or 'missing girls') weighs disproportionally on the resulting SRB. Importantly, the disproportionality effect impacts on the SRB independently of the fertility squeeze, so that both effects combined are cumulative (conceptualised in figure 5).

Practically, the disproportionality effect makes SRB an inadequate indicator to evaluate sex selection trends. In contrast, $\Phi$ is independent from the disproportionality effect and can be readily understood as the prenatal sex selection propensity in a population, reducing the complexity of inferring behavioural change in sex selection practices. $\Phi$ is directly proportional to the prenatal sex selection prevalence, that is, the absolute number of interventions, providing a measure of relative prevalence of sex selection, better suited to investigate changes in prenatal sex selection practices than SRB. We calculated $\Phi$ to re-evaluate SRB trends in India and illustrate our theoretical findings.

\section{Sex selection prevalence and change in India}

In India, fertility transition is well advanced, although with much regional variation. The continuous decline in fertility levels (average number of children per family) combine with an increasing bias in the SRB observed since the 1980 s to the last census in $2011 .^{36}$ Using SRB and total fertility between 1970 and 2010, we calculated the corresponding proportion of couples reverting to sex selection $(\Phi)$ (figure 3). We found that the propensity to sex-select $(\Phi)$ accelerated in the 1990s before reducing intensity, consistent with empirical findings by Jha and colleagues. ${ }^{37}$ Despite a continuous increase in the SRB until 2010 (figure 3A), sex selection propensity $(\Phi)$ reached its peak at the turn of the 21st century, before starting to decline (figure 3B). This finding challenges assumptions that sex selection has continued to increase in the last decade in India (see Discussion and conclusions section). 


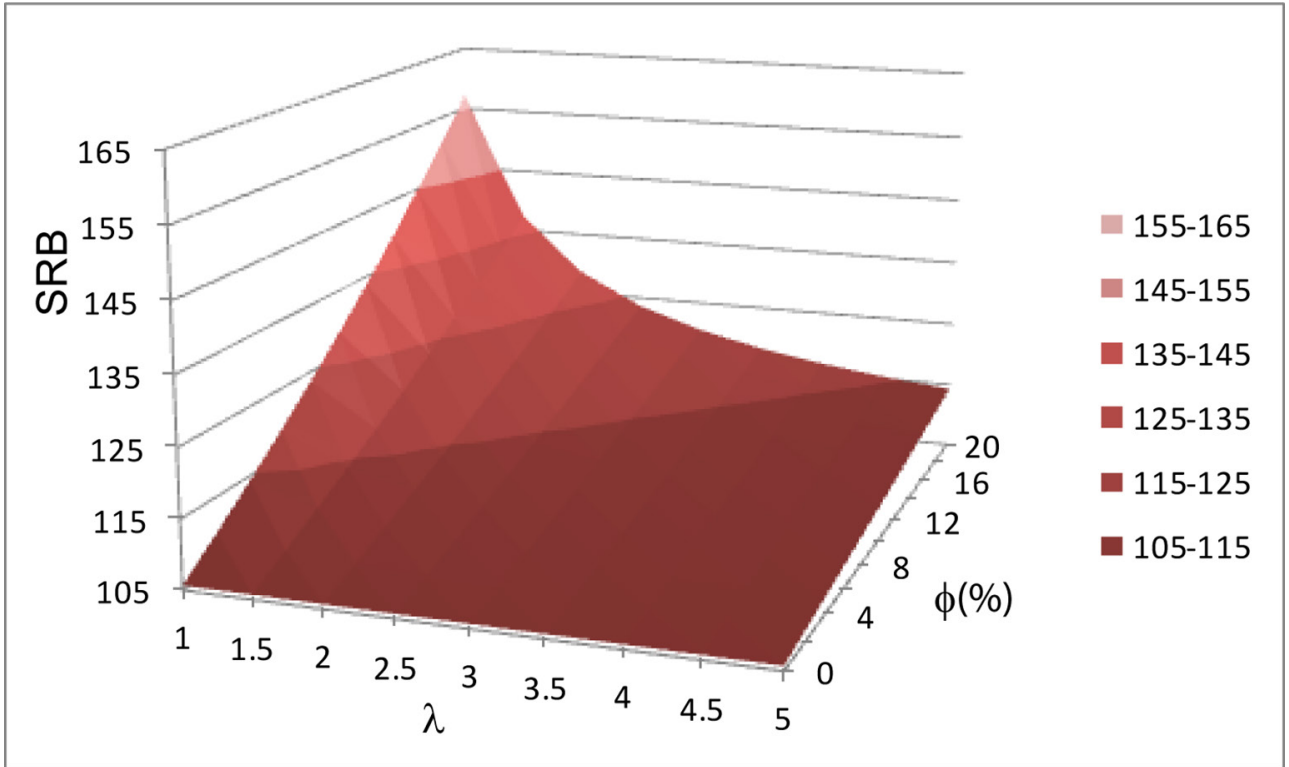

Figure 2 The disproportionality effect of fertility on the sex ratio at birth (SRB), R. R increases with an increasing proportion of intervening couples within a population ( $\Phi, 0-20 \%$ shown). R also increases with a decreasing average number of children within the same population $(\lambda)$. Note that for any constant $\Phi>0$, R still increases with decreasing $\lambda$.

Beyond national trends, we observed pronounced regional differences in fertility and SRB. Rajan et $a l^{36}$ measured an overall increasing bias in the national SRB between the last two censuses $(2001,2011)$. They also found that the SRB bias was stabilising or even reducing in some northern states, where historic trends of excess girls' mortality and high levels of daughter deficit at birth are well known, but was worsening in other parts of the country. Using SRS 2005-2007 3years' average estimates, at the peak of SRB bias in northern India according to the SRS data ${ }^{\text {iv }}$, figure 4 A shows how the ratio of intervening couples $(\Phi)$ relates to fertility across states. We found that sex selection propensity in the population was highest in Rajasthan, Haryana, Uttar Pradesh and Punjab, which exhibit different fertility levels (from 2.1 in Punjab to 4.2 in Uttar Pradesh).

Punjab's highest SRB bias among Indian states is notorious, although in the most recent years it has reduced to levels below Haryana state according to the 2011 census data ${ }^{\mathrm{v}}$. What is of particular interest is that even at its highest SRB bias (figure 4B), Punjab
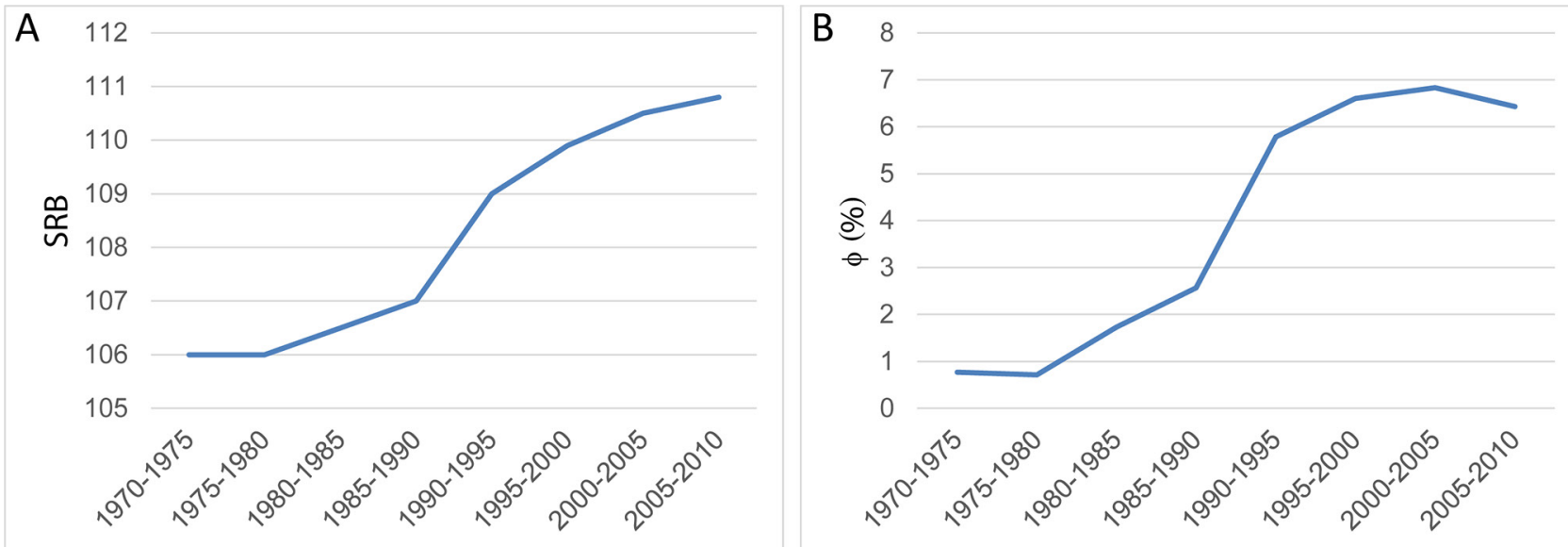

Figure 3 The sex ratio transition in India. (A) SRB national trends, 1970 to 2010. (B) National trends in prenatal sex-selection propensity, 1970 to 2010. Source: UN World Prospect database (observed R and $\lambda$ ). SRB, sex ratio at birth.

\footnotetext{
${ }^{\text {iv }}$ Analyses of the Sample Registration System data suggest that the peak in SRB bias is around 2005 in some northern states now showing a relative decrease.
}

${ }^{\mathrm{v}}$ The accuracy of the very high sex ratio bias at a young age in Jammu and Kashmir reported in 2011 census data is much uncertain (eg, UNFPA report 2014). 
A

\section{(1)}

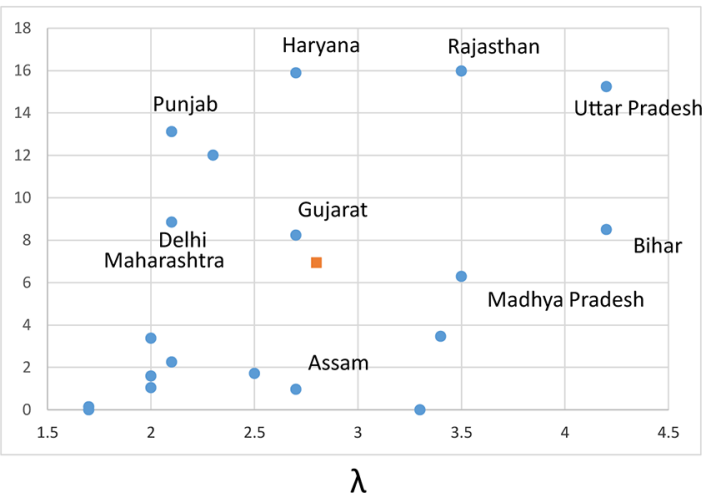

B

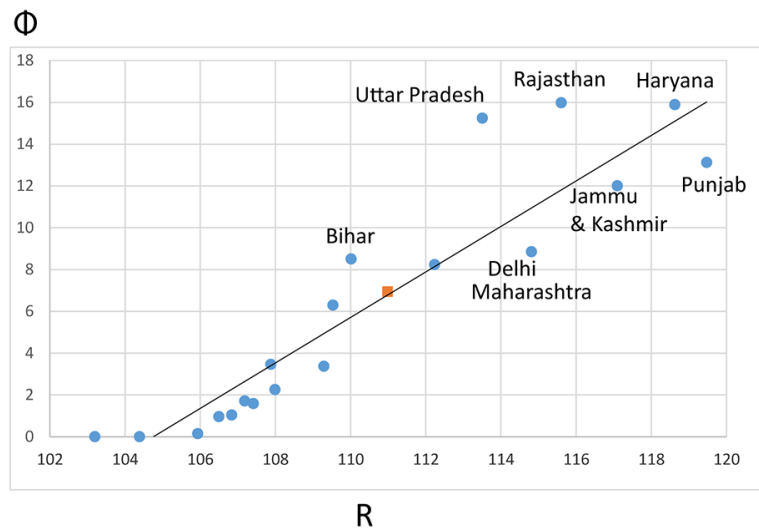

Figure 4 Sex selection prevalence across the main Indian states, in relation to reported fertility level (total fertility rate; TFR) and SRB, 2005-2007. (A) Relationship between reported fertility level $(\lambda)$ and calculated proportion of couples using sex selection $(\Phi) . \lambda$ is estimated using reported period total fertility rates. (B) Relationship between the reported SRB for the main states of India in 2005-2007 with the proportion of couples using sex selection $(\Phi)$. The fitting line represents the expected values of $\Phi$, given R, based on the average relationship between $\Phi$ and R across the main Indian states (solid dots). States above the fitting line (eg, Rajasthan, Uttar Pradesh) have a higher sex selection propensity $\Phi$ than expected given their reported SRB. Those below the fitting line have in contrast a lower measured $\Phi$ than expected considering their SRB. Indian averages in squares. Source: Indian Sample Registration System Statistical Report 2011, tables 15 and 16 (http://www. censusindia.gov.in/vital_statistics/SRS_Reports.html). SRB, sex ratio at birth.

was not the state recording the highest sex selection propensity (figure 4A); the proportion of couples using sex selection was higher in Rajasthan and Utter Pradesh in 2005-2007 (about 16\%), despite a less biased SRB compared with Punjab. The line fit in figure $4 \mathrm{~B}$ shows the average relationship between SRB $(R)$ and the intervening fraction $(\Phi)$. Those states positioned below the regression line have a lower $\Phi$ than the regression to the mean would expect, given their SRB. The disproportionality effect of fertility explains the departure from the mean in figure 4B; the distortion in the SRB is exacerbated in Punjab and Delhi, where fertility is low. In contrast, the effect of each single sex selection weighs less with larger average family sizes in Rajasthan and Uttar Pradesh.

At comparable reported levels of fertility, differences in the proportion of couples intervening can be due to differences in son preference across states and/or additional factors preventing sex selection. For instance, because Punjab and Delhi show similar

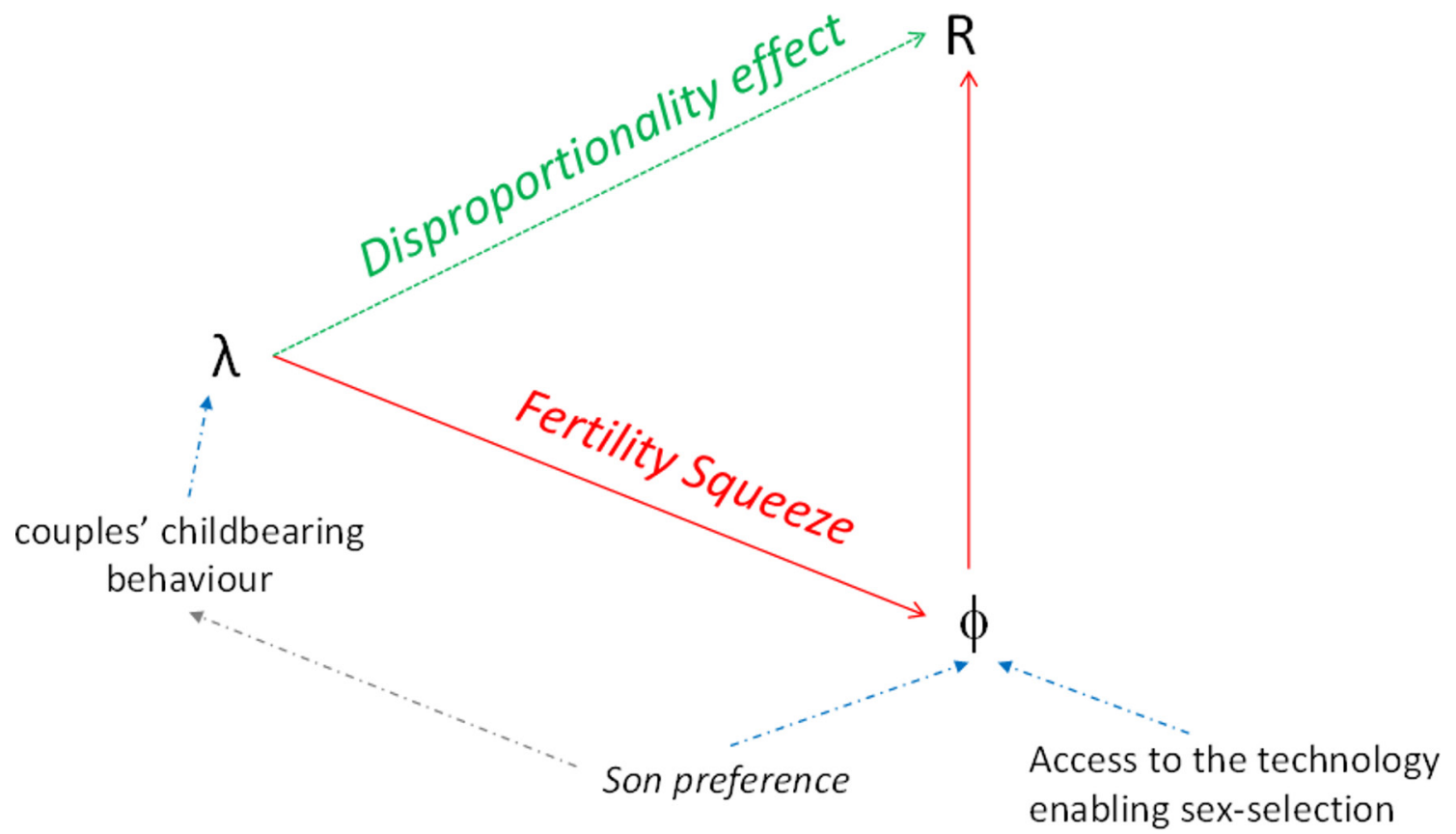

Figure 5 The macro impact of behavioural change: fertility squeeze and disproportionality effects on the sex ratio at birth. 
fertility levels, their difference in $\Phi$ (figure 4A) suggests stronger son preference in Punjab than Delhi, assuming comparable levels of access to the technology in both states.

\section{DISCUSSION}

\section{The hypersensitivity model of fertility on SRB}

Our model elucidated the demographic micro-macro dynamics between PSS and changes in SRB (figure 5). We show that, at low fertility levels, a small proportion of sex-selective procedures suffice to significantly distort the SRB, and importantly an increase in sex ratio bias does not necessarily equate to an increase in sex selection events. This is inconsistent with the fertility squeeze effect. Consequently, the SRB is not an appropriate indicator to evaluate behavioural changes. Figure 5 conceptualises our findings, linking childbearing behaviour and aggregated SRB in a population. Given constant son preference, if more couples want fewer children, more families are at risk of remaining sonless. The relationship between fertility $(\lambda)$ and the proportion of intervening couples $(\Phi)$ reflects the fertility squeeze effect. ${ }^{24}$ The resulting higher proportion of intervening couples $(\Phi)$-and intervening at lower birth order-increases the SRB bias, with the relationship between $\Phi$ and SRB being linear (figure 2).

Perhaps counterintuitively, we show that when the number of children per family is decreasing on average, the SRB bias may still increase despite a decreasing proportion of parents seeking sex-selective intervention. This is because, as we have shown, the impact of each sex selection event on distorting the aggregated SRB varies according to the level of fertility and increases with a reduction of average family size in an exponential relationship. This disproportionality effect is independent of the fertility squeeze effect.

In other words, even if the fertility squeeze effect would not increase the proportion of intervening couples, the SRB would still increase when fertility declines, due to the disproportionality effect. In practice, both effects apply synergistically to distort the SRB. Because both effects follow an exponential function in relation to average family size, the SRB is hypersensitive to levels and change in fertility (figure 2), with important implications for interpreting the SRB. For example in India, the increase in SRB, especially exacerbated in districts well engaged in the fertility transition, ${ }^{15}$ is due to the macro-level disproportionality (figure 4 ). In contrast to the SRB, the proportion of intervening couples $(\Phi)$ is not affected by the disproportionality effect and is readily interpretable to measure PSS trends. We used $\Phi$, that is, the percentage of sex-selecting couples accounting for SRB bias, to re-evaluate trends of PSS in India. $\Phi$ is also directly proportional to the "missing girls' as an expression of sex selection prevalence in a population.
Diffusion of the technology versus disproportionality effect of fertility reduction

Previous empirical research measured a weakening of son preference despite SRB remaining high and even increasing in India ${ }^{25}$ and China. ${ }^{38}$ To explain this apparent paradox, Bhat and Zavier suggested that increased diffusion of sex selection technology could account for this, enabling more (prospective) parents to implement their preferences, despite an overall weakening of gender preference. ${ }^{2532}$ This has led observers to recommend further restricting access to sex selection technology ${ }^{38}$ to control and limit families' opportunities to implement their preferences. Our results offer an alternative explanation. We show that even without increase in sex selection prevalence and even with fewer sex-selective interventions, the SRB may continue to increase, due to the disproportionality effect of fertility reduction, providing quantitative support to suggestions of weakening son preference overall in India. ${ }^{39}$ One possible limitation of the new proposed indicator $(\Phi)$ is that it requires setting a 'natural' SRB benchmark. Several close empirical observations have been proposed in the literature, between 105 and below 106 male births per 100 female births, and some variation across world regions have been documented $^{\mathrm{vi}}$. This has no implications for our theoretical demonstration, but in applied research the calculated proportion of intervening couples would vary slightly depending on the benchmark value adopted. However, importantly, the adoption of a unique benchmark makes $\Phi$ a reliable indicator of sex selection propensity in a population and fully comparable across countries, subregions and over time.

A reversal in sex selection practices has been identified where a reduction in the SRB has been observed, as in South Korea from the late $1990 \mathrm{~s},{ }^{40}{ }^{41}$ or in some cities and regions of China and India. ${ }^{3642} 43$ We demonstrate that in a context of fertility transition, a reversal of sex selection practice precedes the reduction in sex ratio bias. This modifies our understanding of the processes underlying gender population imbalances in Asia as related to development. For example, it challenges the widely held idea that the higher SRB observed among urban and educated women in many studies ${ }^{6} 3744-46$ is due to more sex-selective interventions among these groups. It was proposed that despite weaker son preference among wealthier, educated urban women, ${ }^{25} 4247$ they would have easier access to sex selection procedures to implement their preference compared with rural and lower socioeconomic groups. We show that this is not necessarily the case; educated urban women with smaller families on average would be characterised by the highest SRB bias even if they are not using sex selection more frequently than other socioeconomic groups. The

\footnotetext{
${ }^{\mathrm{vi}}$ Notably the ratio of boys to girls at birth is slightly lower overall in Africa (at about 103 per 100 girls).
} 
gap between rural and urban population SRB bias has narrowed in the last decade in India, but some fertility differences remain. This suggests a higher prevalence of sex selection practice in rural areas, calling for further investigation.

\section{Measure of sex selection propensity to assess intervention}

Our findings have implications for estimating sex selection as well as evaluating policy interventions targeting gender bias. Inferring behavioural change from the masculinisation of the SRB in a context of fertility transition is likely misleading because it is largely due to a scaling (disproportionality) effect. Despite a continuous increase in the SRB and the diffusion of sex selection technology ${ }^{\text {vii }}{ }^{17}{ }^{25}$ we measured a decrease in the recent trend in sex selection propensity in India (figure 4). This points to a significant weakening of son preference and suggests that policy intervention may have been effective in curbing sex selection and raising daughters' valuation, although the impact of specific schemes remains to be evaluated. For example, in an evaluation of CCT schemes to improve girl children's status in Haryana, Krishnan et al found, despite an improvement in girls' immunisation, an increasing bias in the SRB over the study period (sample across 28 villages), producing an apparent paradox. ${ }^{48}$ However, increasing SRB bias does not necessarily indicate a failure of the intervention to limit sex selection. In fact, fewer couples might be using PSS if fertility has reduced. An estimation of the propensity of sex selection $(\Phi)$, derived from the combined SRB and fertility levels within the population surveyed, would be a more reliable indicator to evaluate the impact of interventions to promote the girl child.

Sex selection propensity and the proportional sex selection prevalence (ie, the total number of sex selection interventions) directly indicate the risk and spread, respectively, of sex selection interventions. Because policy interventions aiming to reduce sex selection and SRB bias act on $\Phi$-either by reducing son preference (eg, child protection schemes) or access to sex selection technologies (eg, PNDT) — we recommend using trends in sex selection propensity $(\Phi)$ to inform the medical profession and assess policy interventions. Further, our findings suggest that policy initiatives targeting changes in gender representations and preferences to address sex ratios imbalances should be encouraged. Nonetheless, SRB remains an appropriate indicator for future population sex imbalances, important for concerns about future societal impacts of the marriage market squeeze. ${ }^{49} 50$

What would happen in a scenario of increasing fertility? Although the impact of the recent relaxation of the "one child policy' on increasing fertility in China remains

\footnotetext{
${ }^{\text {vii }}$ Counteracting the diffusion of medical equipment, enforcement of the law potentially can reduce access to prenatal sex determination, although in practice its impact is thought to remain limited in North India (eg, UNFPA 2014).
}

uncertain, if Chinese fertility rises in the near future, this will help reduce SRB imbalances. However, assuming continuous access to intervention methods without a change in gender preference, the SRB bias would reduce without reduction in sex selection prevalence or even despite an increase in the number of sex selections.

Acknowledgements The authors are grateful to John Skilling for greatly simplifying the derivation of equation (7); to Jörg Schumacher for constructive conversations and his helpful comments on the manuscript; and to Surrinder Cheema, Jane Ferguson, Kevin Gatter, Ashok Handa, David Hughes, Jaideep Pandit and Andrew Parker for providing medical feedback. Thanks to Bernice Kuang for editing support. Thanks also to the participants at the Population Association of America conferences 2014 and 2017 for their feedback on initial presentations of our model.

Contributors SD oversaw the research, conceived the conceptual model, conducted Indian data analysis and wrote the paper. DSS conceived and developed the mathematical models, and contributed to writing of the paper.

Funding This work was supported by grants to SD from the UK Economic and Social Research Council (ES/N01877X/1), the Nuffield Foundation (Grant $\mathrm{CPF} / 37731$ ) and the University of Oxford, Social Sciences Division, Returning Carers' Fund 2015.

Competing interests None declared.

Patient consent Not required.

Provenance and peer review Not commissioned; externally peer reviewed. Data sharing statement № additional data are available.

Open access This is an open access article distributed in accordance with the terms of the Creative Commons Attribution (CC BY 4.0) license, which permits others to distribute, remix, adapt and build upon this work, for commercial use,

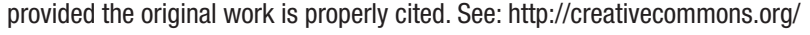
licenses/by/4.0/

C Article author(s) (or their employer(s) unless otherwise stated in the text of the article) 2018. All rights reserved. No commercial use is permitted unless otherwise expressly granted.

\section{REFERENCES}

1. Park $\mathrm{CB}, \mathrm{Cho} \mathrm{N}-\mathrm{H}$. Consequences of son preference in a low-fertility society: imbalance of the sex ratio at birth in Korea. Popul Dev Rev 1995;21:59-84.

2. Zeng Y, Tu P, Gu B, et al. Causes and implications of the recent increase in the reported sex ratio at birth in China. Population And Development Review 1993;19:283.

3. Arnold F, Kishor S, Roy TK. Sex-Selective Abortions in India. Popul Dev Rev 2002;28:759-85.

4. das Gupta M, Mari Bhat PN. Fertility decline and increased manifestation of sex bias in India. Popul Stud 1997;51:307-15.

5. Guilmoto $\mathrm{CZ}$, Hoàng $X$, Van TN. Recent increase in sex ratio at birth in Viet Nam. PLoS One 2009;4:e4624.

6. Frost MD, Puri M, Hinde PR. Falling sex ratios and emerging evidence of sex-selective abortion in Nepal: evidence from nationally representative survey data. BMJ Open 2013;3:e002612.

7. Duthé G, Meslé F, Vallin J, et al. High Sex Ratios at Birth in the Caucasus: Modern Technology to Satisfy Old Desires. Popul Dev Rev 2012;38:487-501.

8. Dubuc S, Coleman D. An increase in the sex ratio of births to Indiaborn Mothers in England and Wales: evidence for Sex-Selective Abortion. Popul Dev Rev 2007;33:383-400.

9. Almond D, Edlund L, Milligan K. Son preference and the persistence of culture: evidence from South and East Asian Immigrants to Canada. Popul Dev Rev 2013;39:75-95.

10. Abrevaya J. Are there missing girls in the United States? Evidence from birth data. Am Econ J Appl Econ 2009;1:1-34.

11. Almond D, Edlund L. Son-biased sex ratios in the 2000 United States Census. Proc Natl Acad Sci U S A 2008;105:5681-2.

12. Bongaarts J, Guilmoto C. How many more missing women? Lancet 2015;386:427.

13. Boada M, Carrera M, De La Iglesia C, et al. Successful use of a laser for human embryo biopsy in preimplantation genetic diagnosis: report of two cases. J Assist Reprod Genet 1998;15:302-7. 
14. Mayor S. Specialists question effectiveness of sex selection technique. BMJ 2001;323:67.

15. Mohanty SK, Rajbhar M. Fertility transition and adverse child sex ratio in districts of India. J Biosoc Sci 2014;46:753-71.

16. Roy TK, Chattopadhyay A. Daughter discrimination and future sex ratio at birth in India. Asian Popul Stud 2012;8:281-99.

17. Sudha S, Irudaya RS, Rajan SI. Female demographic disadvantage in India 1981-1991: sex selective abortions and female infanticide. Dev Change 1999;30:585-618.

18. UNFPA. Sex ratios and gender biased sex-selection. History, debates and future directions: UNFPA report, 2014:62.

19. Anukriti S. Financial incentives and the fertility-sex ratio trade-off. Am Econ J Appl Econ 2018;10:27-57.

20. Nandi A, Deolalikar AB. Does a legal ban on sex-selective abortions improve child sex ratios? Evidence from a policy change in India. $J$ Dev Econ 2013;103:216-28.

21. Sekher TV. Special financial incentive schemes for the girl child in India: a review of select schemes. New Delhi: United Nations Population Fund ed, 2012.

22. WHO. Preventing gender-biased sex selection: an interagency statement OHCHR, UNFPA, UNICEF, UN Women and WHO, 2011:26.

23 Dubuc S. Son preference and fertility: An overview. In: Basten $\mathrm{S}$, Casterline J, Choe M, eds. Family demography in Asia a comparative analysis of fertility preferences: Edward Elgar, 2017. forthcoming.

24. Guilmoto CZ. The sex ratio transition in Asia. Popul Dev Rev 2009;35:519-49.

25. Bhat PN, Zavier AJ. Fertility decline and gender bias in northern India. Demography 2003;40:637-57.

26. Poston DL, Gu B, Liu PP, et al. Son preference and the sex ratio at birth in China: a provincial level analysis. Soc Biol 1997;44:55-76.

27. Retherford R, Roy T. Factors affecting sex-selective abortion in India and 17 major states: National Family Health Survey Subject Reports, 2003:78.

28. Jayachandran S. Fertility decline and missing women. Am Econ J Appl Econ 2017:9:118-39.

29. Clark S, Shelley C. Son preference and sex composition of children: evidence from India. Demography 2000;37:95-108.

30. Yamaguchi K. A formal theory for male-preferring stopping rules of childbearing: sex differences in birth order and in the number of siblings. Demography 1989;26:451-65.

31. Basu D, de Jong R, Rd J. Son targeting fertility behavior: some consequences and determinants. Demography 2010;47:521-36.

32. Bongaarts $\mathrm{J}$. The implementation of preferences for male offspring. Popul Dev Rev 2013;39:185-208.

33. Croll EJ. Fertility decline family size and female discrimination: a study of reproductive management in East and South Asia. AsiaPacific Population Journal 2002;17:11-38.
34. Grech V, Savona-Ventura C, Vassallo-Agius P. Research pointers: unexplained differences in sex ratios at birth in Europe and North America. BMJ 2002;324:1010-1.

35. Parazzini F, La Vecchia C, Levi F, et al. Trends in male:female ratio among newborn infants in 29 countries from five continents. Hum Reprod 1998;13:1394-6.

36. Rajan S, Srinivasan S, Bedi A. Coming back to normal? Census 2011 and sex ratios in India. Economic \& Political Weekly 2015;1:33-6.

37. Jha P, Kesler MA, Kumar R, et al. Trends in selective abortions of girls in India: analysis of nationally representative birth histories from 1990 to 2005 and census data from 1991 to 2011. Lancet 2011;377:1921-8.

38. Zhou C, Wang XL, Zhou XD, et al. Son preference and sex-selective abortion in China: informing policy options. Int $J$ Public Health 2012;57:459-65.

39. Gupta MD, Chung W, Shuzhuo L. Evidence for an incipient decline in numbers of missing girls in China and India. Popul Dev Rev 2009;35:401-16

40. Chung W, Gupta MD. The decline of son preference in South Korea: the roles of development and public policy. Popul Dev Rev 2007;33:757-83.

41. Kashyap R, Villavicencio F. The dynamics of son preference, technology diffusion, and fertility decline underlying distorted sex ratios at birth: a simulation approach. Demography 2016:53:1261-81.

42. Kaur R, Bhalla SS, Agarwal MK, et al. Sex ratio at birth. the role of gender, class and education: UNFPA technical report, 2016:43.

43. Jiang Q, Yu Q, Yang S, et al. Changes in sex ratio at birth in china: a decomposition by birth order. J Biosoc Sci 2017;49:826-41.

44. Agnihotri SB. Sex ratio patterns in the Indian population. New Delhi: Sage Publications, 2000.

45. Chaudhri DP, Jha R. India's gender bias in child population, female education and growing prosperity: 1951-2011. Int Rev Appl Econ 2013;27:23-43.

46. Guilmoto CZ, Ren Q. Socio-economic differentials in birth masculinity in China. Dev Change 2011;42:1269-96.

47. Pande RP, Astone NM. Explaining son preference in rural India: the independent role of structural versus individual factors. Popul Res Policy Rev 2007;26:1-29.

48. Krishnan A, Armarchand R, Byass P, et al. No one says 'No' to money - a mixed methods approach for evaluating conditional cash transfer schemes to improve girl children's status in Haryana, India. International Journal for Equity in Health 2014;13.

49. Hesketh $T$, Xing ZW. Abnormal sex ratios in human populations: causes and consequences. Proc Natl Acad Sci U S A 2006;103:13271-5.

50. Holden C. Demography. Chinese men: a rising tide of troublemakers? Science 2009;323:1166-66. 